\title{
O Atualismo entre uniformitaristas e catastrofistas
}

\author{
Actualism between uniformitarianists and catastrophists
}

\author{
FELIPE FARIA \\ Universidade Federal de Santa Catarina | UFSC
}

\begin{abstract}
RESUMO No século XIX introduziu-se na Geologia a teoria uniformitarista, que se baseava na reprodução uniforme dos dados observáveis em fenômenos geológicos atuais, para interpretação da ocorrência destes fenômenos no passado. Seus defensores procuravam refutar o Catastrofismo, que, por sua vez, procurava explicar a mesma configuração, fundamentando-se na ocorrência pretérita de fenômenos geológicos, frequentemente mais intensos que os observáveis atualmente. Apesar das discordâncias epistemológicas entre estas teorias, ambas utilizavam o método atualista, que extrapolava, sem radicalismos, os fenômenos observáveis na atualidade, para explicar fenômenos pretéritos. Este artigo discutirá este ponto de confluência entre o Catastrofismo e o Uniformitarismo, teorias com objetivos cognitivos divergentes.
\end{abstract}

Palavras-chave atualismo - catastrofismo - uniformitarismo - método comparativo - objetivos cognitivos.

\begin{abstract}
In the nineteenth century, the uniformitarian theory was introduced in geology, which was based on the uniform reproduction of observable data on current geological phenomena, to interpret the occurrence of these phenomena in the past. Their proponents sought to refute Catastrophism, which, in turn, sought to explain the same setting, basing himself in the occurrence of geological phenomena in the past, often more severe than currently observable. Despite the epistemological disagreements between these theories, both used the actualist method, which would yield without radicalism, the observable phenomena in the present, to explain phenomena in the past. This article will discuss this point of confluence between Catastrophism and Uniformitarianism, cognitive theories with divergent goals.
\end{abstract}

Keywords actualism - catastrophism-uniformitarianism-comparative method-cognitive goals.

\section{Catastrofistas atualistas}

Na área da Geologia a aplicação do método atualista já se fazia intenso, quando o geólogo suíço, Jean-André De Luc (1727-1817), defendeu seu uso, formulando posteriormente o termo "causas atuais" para descrever os processos geológicos aos quais o Globo se submetia na atualidade e que tinham sido responsáveis pela configuração geológica da Terra. De Luc defenderia que a interpretação dos dados provenientes do registro geológico deveria ser executada por meio da comparação com os processos em ação na atualidade.

Primeiramente, ele utilizaria este método para explicar a formação das rochas do Secundário ${ }^{1}$ e dos períodos mais recentes, uma vez que somente as rochas primárias ${ }^{2}$ não apresentavam os principais vestígios que podiam ser interpretados à época: os fósseis. ${ }^{3}$ Desta maneira, ele distinguia os períodos geológicos entre aqueles em que era possível aplicar o método atualista e nos quais esta aplicação estava impossibilitada pela falta de elementos comparativos. De Luc estenderia este modelo binário de explicação à distinção que fazia entre os períodos ocorridos antes e após a última revolução. Para ele, este seria um evento catastrófico, tal como uma inundação relacionada ao dilúvio bíblico, e era um marco divisor da geo-história, pois iria dividi-la entre mundos pré e pós-diluvianos. Mas, ainda assim, 
ele defenderia para a compreensão destes dois mundos ou períodos a aplicação do método atualista na interpretação dos seus dados no registro geológico.

A ocorrência do dilúvio, que De Luc defendia, teria como causa alguns dos processos geológicos operantes também na atualidade, porém, ele não os identificava precisamente. Contudo, à diferença dos processos atuais, a operação dos agentes envolvidos neste processo geológico catastrófico teria ocorrido com uma intensidade maior. ${ }^{4}$ Esta variação de intensidade seria a única causa extraordinária a ser invocada na explicação de De Luc. Por todo 0 restante, ele prosseguia utilizando as causas atuais como modelo comparativo.

Alguns anos mais tarde, James Hutton (1726-1797) também utilizaria a abordagem atualista para expor sua “Teoria da Terra", ${ }_{5}^{5}$ que defendia haver um extremo equilíbrio entre o resultado dos agentes envolvidos nos processos geológicos. Esta teoria, que resultava na concepção de um "estado estacionário" na história geológica do Globo, receberia um grande apoio com a publicação de um livro ilustrativo, escrito por John Playfair (1748-1819). ${ }^{6}$ Ao defender o potencial heurístico da teoria huttoniana, esta obra contribuiu significativamente para sua aceitação por parte da comunidade científica e do público culto em geral, visto que muitos dos livros nos quais estas ideias e discussões eram expostas, como, por exemplo, este de Playfair, tinham ampla circulação entre estas parcelas da sociedade.?

Este também foi o caso do livro de Georges Cuvier (1769-1832), Investigações sobre as ossadas fósseis de quadrúpedes (1812), a obra mais editada sobre a divulgação de suas ideias para a História Natural. Neste trabalho, Cuvier expôs sua teoria catastrofista defendendo que os fenômenos envolvidos na dinâmica geológica e observáveis na atualidade não eram suficientes para explicar as rupturas de continuidade, constantes no registro geológico. Estas descontinuidades podiam ocorrer durante o processo de sucessão faunística, que era gerado pela ocorrência de uma revolução. Esta extinguiria a fauna de uma localidade, que era posteriormente repovoada por outra migrante, proveniente de alguma localidade não atingida por aquele evento catastrófico. Desta maneira, o registro geológico, que mostrava uma sucessão de estratos contendo fósseis de um grupo faunístico, sofria uma interrupção representada pela ocorrência de um estrato formado por uma catástrofe. Neste estrato constariam os últimos representantes locais daquela fauna, já que seria extinta por uma revolução. Assim sendo, a teoria do Catastrofismo adotava um modelo explicativo baseado em uma descontinuidade do registro geológico. ${ }^{8}$

Todavia, apesar desta posição, vários catastrofistas, como o próprio Cuvier, acreditavam que esta ruptura, produzida nas ocasiões de ocorrência das catástrofes, não seria excludente de uma continuidade nos processos geológicos operantes entre elas. Nestes períodos de relativa "tranquilidade" geológica, processos da dinâmica geológica, lentos e graduais, estariam operando de uma maneira análoga à que poderia ser verificada nos processos em operação na atualidade. Deste modo, os períodos geológicos mais recentes poderiam ser estudados com maior precisão, logo apresentariam uma semelhança maior com os processos atuais, facilitando assim sua interpretação.

Em decorrência desta maior precisão, Cuvier defendia que as análises dos estratos deveriam ser realizadas na ordem inversa de sua cronologia, ou seja, indo dos mais recentes (mais superficiais) aos mais antigos (mais profundos), pois com isso os modelos comparativos seriam evidenciados em primeiro lugar. ${ }^{9} 0$ princípio atualista também era aplicável nos métodos anátomo-comparativos de Cuvier, porque, na reconstrução de um animal extinto a partir de um único osso fossilizado, era necessário o emprego de um modelo comparativo completo que, neste caso, seria um animal vivente atual.

Segundo os catastrofistas, no período atual em que vivemos, iniciado pela ocorrência da última revolução, 0 Globo encontrar-se-ia submetido a mais uma situação de relativa estabilidade geológica, estando em operação apenas alguns agentes principais que contribuiram para alterar a atual configuração de sua superfície: chuvas e degelo, águas correntes, o mar e vulcões. ${ }^{10}$ Seriam os mesmos tipos de processos que também operaram nas revoluções, no entanto, neste caso, os agentes atuantes teriam operado com maior intensidade.

A falta de uma explicação causal para esta variação de intensidade não bloqueava a argumentação da teoria catastrofista, desde que na atualidade os fenômenos geológicos também operavam variando o grau de sua intensidade, entretanto em menor magnitude do que durante as catástrofes. Este caráter intenso e/ou súbito destas revoluções 
podia ser constatado mediante configuração da distribuição geral dos fósseis, como, por exemplo, as conchas marinhas fossilizadas encontradas em topos de montanhas, e na formação de estratos geológicos contendo fragmentos de rochas de localidades distantes. ${ }^{11}$

Mas, para que estes registros fossilíferos ou geológicos se tornassem "documentos" históricos, como Cuvier defendia, era necessária uma interpretação dos dados que eles exibiam. E o método de maior valor heurístico para interpretá-los, à disposição naquele momento, era o atualista. Neste, consoante Charles Lyell (1797-1875), as "causas atuais" seriam o "alfabeto e a gramática" que possibilitariam ler o "livro" da Geologia. Com esta metáfora, Lyell estava defendendo o Atualismo como o fundamento pelo qual muitas questões seriam resolvidas, ao mesmo tempo em que outras seriam levantadas em razão dos novos dados produzidos por aquela mesma resolução. ${ }^{12}$

Ainda por algum tempo, a invocação de graus extraordinários da operação dos agentes atuantes para explicar estas questões receberia grande aceitação da comunidade científica. Mesmo após Lyell ter feito a exposição de sua teoria uniformitarista de maneira minuciosa e bem amparada em dados coletados em campo, sua insistência na extrema utilização do Atualismo Ihe causaria várias dificuldades para avançar na reforma que ele propunha para a Geologia.

\section{Uniformitaristas atualistas}

À época em que Lyell publicou sua grande obra, o Princípios de Geologia (1830-1833), , 33 Georges Cuvier já tinha avançado há muito tempo em seu objetivo de expurgar a História Natural dos "Sistemas" explicativos das causas envolvidas em sua dinâmica. ${ }^{14}$ Este expurgo foi declarado por Lyell como importante para o desenvolvimento da Geologia até aquela ocasião, porém aquele seria o momento de retomar as inquirições causais na Geologia nos estudos sobre a crosta terrestre..$^{15}$ Tal proposta reformatória dos objetivos cognitivos desta área científica visava estabelecer princípios de raciocínio, que Lyell utilizava para embasar sua teoria e que, na percepção dele, tornar-se-iam determinantes para todas as áreas das Ciências. ${ }^{16}$

Baseados na noção newtoniana de vera causa, estes princípios estariam relacionados à proposta de utilização das "causas atuais" como modelo comparativo. ${ }^{17}$ Seriam eles: o Atualismo, que tratava diretamente da utilização destas causas como elemento explicativo das configurações geológicas e biológicas atuais; o Uniformitarismo, que intensificaria a aplicação do primeiro, ao defender que os processos geológicos sempre atuaram com o mesmo grau de intensidade; e o "estado estacionário", que Lyell reviveu da teoria de Hutton e que seria um dos maiores pontos de rejeição em sua teoria. ${ }^{18}$

Este último princípio, que propõe um extremo equilíbrio entre os agentes da dinâmica geológica, conduziria a um sistema de balanço em que eles estariam continuamente neutralizando seus efeitos entre si. Neste sistema estável não haveria espaço para uma direcionalidade, muito menos para uma progressividade, na ocorrência dos fenômenos naturais. 0 balanceamento dos efeitos dos agentes geológicos geraria uma ciclicidade das mudanças da crosta, porque 0 efeito destas era constantemente balanceado pelo efeito de subsequentes mudanças, formando assim um ciclo. ${ }^{19}$

Defender um princípio como este não seria uma tarefa simples em uma comunidade científica que já contava com uma enorme quantidade de evidências da existência de um caráter direcional na história do Globo. A maior parte destas evidências era proveniente do registro fossilífero, que também já havia proporcionado a comprovação da ocorrência do fenômeno natural da extinção. Este, por sua vez, auxiliava a aceitação de uma direcionalidade, pois cada vez que uma localidade fosse atingida por uma catástrofe uma fauna era extinta, e, somente após esta revolução, aquela localidade seria repovoada. Tal situação estava representada no registro fossilífero, que, conforme os catastrofistas, evidenciava esta sucessão biótica direcional onde os eventos não se repetiam, e, conseqüentemente, jamais uma fauna reaparecia.$^{20}$ 
Décadas mais tarde, Lyell enfraqueceria sua defesa da utilização do princípio do "estado estacionário", não só em virtude das evidências levantadas pelos trabalhos que iam surgindo na área da Geologia e Paleontologia, como também em função do posicionamento que ele passaria a ter após a aceitação da teoria da Unidade de Tipo ${ }^{21}$ de Charles Darwin (1809-1882). ${ }^{22}$

Num primeiro momento, Lyell seria um pouco ambíguo com relação àquela teoria, contudo, a partir das descobertas de inequívocos fósseis humanos realizadas no final da década de 1950, ele aderiu a uma interpretação evolucionária da geohistória, que era direcional, e assim abandonou a defesa do princípio do "estado estacionário". ${ }^{23}$

Os dois outros princípios, Atualismo e Uniformitarismo, continuaram compondo a base de sua Geologia, sendo que este último continuaria a sofrer diversas críticas. Dentre estas, incluíam-se as de William Whewell (1794-1866), feitas em sua revisão do primeiro volume dos Princípios de Geologia de Lyell (1830). Whewell destacou a importância daquele trabalho para o desenvolvimento da Geologia, todavia rejeitou a ideia de uma extrema aplicação do método atualista, constante no Uniformitarismo. ${ }^{24} \mathrm{Em} 1832$, Whewell fez a revisão do segundo volume do livro de Lyell, no qual apontaria a uma consensual aplicação do Atualismo por parte da comunidade científica, a qual teria sido adotada em função da sua "mais fecunda evidência". ${ }^{25}$

Além disso, ele também destacou o isolamento sofrido por Lyell ao insistir na extrema aplicação do princípio atualista. Na concepção de Whewell, este posicionamento de Lyell estava dividindo os geólogos em duas "facções" (sic.), que ele passou a denominar de "catastrofistas" e "uniformitaristas". ${ }^{26}$ E esta constatação podia ser estendida para a situação de Lyell no tocante à comunidade científica da Europa continental. ${ }^{27}$

Isolado como uniformitarista, Lyell também seria criticado fora da Inglaterra quanto à sua insistência no uso extremo do princípio do Atualismo. Assim como na Europa insular, a comunidade científica continental, que há algum tempo usava este método, somente refutaria a forma extrema como Lyell o utilizava, a qual resultava em seu Uniformitarismo. ${ }^{28}$

\section{Catastrofismo e uniformitarismo em transição}

A utilização do Atualismo já estava tão bem estabelecida entre a comunidade científica da primeira metade do século XIX que trabalhos produzidos sob esta orientação recebiam enorme aceitação entre catastrofistas e uniformitaristas. Um exemplo simbólico desta situação é evidenciado pela citação que Lyell e seu colega, Roderick Murchison (1792-1871), ${ }^{29}$ fariam a um trabalho de dois naturalistas cuvierianos, que apresentava diversas conclusões atualistas. ${ }^{30}$

Jean-Baptiste Croizet (1787-1859) e Antoine Claude Jobert (? -1855) estavam estudando a geologia da região central da França - Auvérnia -, quando Lyell e Murchison viajavam por aquela localidade e conheceram os fósseis de mamíferos extintos que estavam sendo escavados em estratos onde não constavam restos de organismos marinhos. De acordo com seu estado de conservação, aqueles fósseis não pareciam ter sido extintos por algum evento catastrófico, muito menos por uma transgressão marinha. Estes dados apoiavam a constatação anterior daqueles dois naturalistas franceses sobre os depósitos geológicos de basalto e rochas vulcânicas, que, na opinião deles, demonstravam ter sido formados de modo lento e gradual. Alguns destes depósitos preservavam a configuração original dos vales em que eram formados e, desta maneira, permitiam análises do seu processo de erosão ao longo do tempo. Como se tratavam de diversos depósitos formados por derramamentos de lava ocorridos em ocasiões separadas, várias conformações do vale estavam representadas e ordenadas sequencialmente e, assim, evidenciavam a existência de uma cronologia na deposição do material vulcânico.

Levando-se em conta este ordenamento dos depósitos, o tempo requerido para sua formação e também o bom estado de preservação dos fósseis, Croizet e Jobert não utilizaram a hipótese catastrofista e pensaram em termos de uma ação de "causas análogas as atuais". ${ }^{31} 0$ livro em que ambos apresentaram estes dados, além de ser dedicado à Cuvier, também reproduzia a formatação de sua grande obra, iniciando com um "discurso preliminar" e tendo como título: Investigações sobre as ossadas fósseis de quadrúpedes do departamento de Puy-de-Dôme. ${ }^{32}$ No entanto, ao 
descartar uma explicação catastrofista em detrimento de uma atualista, este trabalho recebeu o seguinte comentário de Cuvier: "... eles entram nesta ordem de especulações da qual a Academia ${ }^{33}$ pouco aprecia de se ocupar. Entretanto, isto não tira nada do mérito da obra, que consiste sobretudo em fazer conhecer grande quantidade de espécies fósseis antes desconhecidas, e confirmar mais e mais esta presunção exposta pelo relator, que o que tem sido descoberto neste gênero (de pesquisa), não passa de uma pequena parte do que resta ser descoberto." ${ }^{34}$

Lyell e Murchison também aprovariam o trabalho de Croizet e Jobert, indo além de Cuvier em seus comentários, ao afirmar que a inferência dos naturalistas franceses sobre uma gradual sucessão dos estratos era suportada pela hipótese de que um enorme intervalo de tempo haveria decorrido, e esta hipótese, por sua vez, se apoiava na existência daquela grande quantidade de depósitos de material vulcânico dispostos sucessivamente. Eles ainda aproveitariam seu trabalho para avançar na refutação do Catastrofismo, discorrendo sobre seu uso como método e como esta utilização não passava de um recurso apelativo para problemas de solução praticamente impossível. ${ }^{35}$

Essa refutação era importante para Lyell, pois, segundo ele, o trabalho de Cuvier sobre as formações do Terciário 36 de Paris, realizado em conjunto com o mineralogista Alexandre Brongniart (1770-1847), e de profunda orientação catastrofista, havia "retardado seriamente o desenvolvimento da Geologia", apesar de ter marcado uma "era" nesta Ciência.

Naquele estudo estratigráfico, Cuvier e Brongniart concluíram que os estratos geológicos poderiam ser identificados por intermédio do seu conteúdo fossilífero, e ampliaram, assim, as áreas de abrangência dos estudos, por conseguinte os estratos geológicos podiam, a partir de então, ser correlacionados, mesmo que fossem descontínuos. Com essa inovação, os mapas geológicos puderam abranger áreas cada vez maiores. Mas, além deste novo uso, Lyell utilizaria este princípio de correlação e a grande gama de dados levantados pelos estudos das formações do Terciário para avançar em uma ideia que lhe conduziria às suas conclusões uniformitaristas.

Utilizando também os estudos de Giovanni Battista Brocchi (1772-1826), Constant Prévost (1787-1836) e Barthélemy de Basterot (1800-1887), sobre as formações do Terciário do norte da Itália, de Paris e da região do sul da França, respectivamente, Lyell percebeu que poderia arranjar os grupos de animais fossilizados constantes nos estratos em assembleias. Este arranjo poderia facilitar a caracterização de um determinado estrato e também possibilitar 0 estabelecimento de uma relação quantitativa com as espécies viventes da região. Esta relação poderia indicar a idade das formações e das próprias espécies agrupadas, porque ocorria logo mediante a comparação do número de espécies viventes e de espécies fósseis pertencentes aos estratos. ${ }^{37}$

Com o propósito de dar continuidade a esta ideia, Lyell contratou os serviços de uma das maiores autoridades em conchas fósseis do Terciário, Gérard-Paul Deshayes (1796-1875), , ${ }^{38}$ que lhe forneceu um grande aporte de dados sobre este tipo de fauna fóssil, porém, ainda assim, não lhe garantiu uma boa aceitação do novo método que ele propunha. Esta situação era decorrente de uma dificuldade empírica, tal como: a falta de definição nos limites de variação intra e interespecífica, que comprometia o estabelecimento das relações quantitativas entre os grupos fósseis e viventes. ${ }^{39}$

Contudo, por meio deste trabalho, Lyell pôde perceber que, ao longo do tempo, ocorreram mudanças no mundo orgânico e inorgânico, e que elas se deram em uma escala lenta, gradual e contínua. Baseado na grande quantidade dos fósseis estudados, os quais tiveram os estratos onde se encontravam muito bem descritos, Lyell também constataria a enormidade de tempo que se passara para acomodar todos os processos envolvendo aquelas mudanças. Isso ocorreu por todo o Terciário, e este dado poderia ser extrapolado de modo extremamente atualista para os outros períodos geológicos. Com estas ideias nascia então o Uniformitarismo de Lyell.

Aquela proposta de extrapolação contrariava diretamente a ideia de Cuvier de que as causas atuais seriam inadequadas para explicar todos os eventos geológicos que tiveram vez na história do Globo. Alguns destes eventos deviam ter sido provocados por agentes atuais, operando com uma intensidade extraordinária. Paradoxalmente, Lyell chegaria a uma conclusão semelhante, quando analisou o fenômeno dos "Blocos Erráticos". ${ }^{40}$ Na visão dele, a distribuição aleatória destas rochas alóctones teria ocorrido mediante seu transporte em massas de gelo flutuantes durante um período no qual a região envolvida estaria submersa por causa de algum tipo de evento catastrófico. 
Diferentemente dos catastrofistas, Lyell pensava em eventos pontuais que combinavam os processos atuais, de modo que estes resultassem emergencialmente em uma ação de maior intensidade, como, por exemplo, uma inundação provocada pelo vazamento das águas de um lago glacial. A formação destes lagos teria ocorrido lenta e gradualmente, em decorrência da formação de barreiras naturais em vales que tinham rios operando. Com estas barragens os rios seriam represados, formando lagos com o gradual acúmulo das águas. Todavia, um processo atual, como um terremoto, poderia fazer ruir aquela barragem, fazendo com que as águas vazassem subitamente, arrastando consigo rochas de grandes dimensões. Este era um processo geológico catastrófico, porém gerado em uma combinação conjuntural de processos atuais. ${ }^{41}$

\section{Considerações finais}

Os métodos comparativos demandam a utilização de modelos que servem como referenciais para a análise a ser executada. Se esta for a análise de um processo já encerrado, somente seus vestígios e resultados poderão ser verificados. E, para que esta verificação indireta se torne possível, deverão ser utilizados como modelos comparativos os processos atuais - "causas atuais".

Foi assim com a Anatomia Comparada de Cuvier, um dos maiores difusores do Catastrofismo. Para reconstruir os seres vivos representados somente na forma fóssil, Cuvier os comparava com os animais viventes - atuais. No entanto, no que se refere às suas explicações no campo da Geologia, ele entendia que a intensidade de alguns dos processos ocorridos no passado fora diferente da ocorrida em processos operando na atualidade. Esta diferença de intensidade podia caracterizar o processo em questão como sendo ele mesmo extraordinário e não apenas sua magnitude.

Sob a ótica de Cuvier, esse caráter extraordinário também podia ser verificado na ocorrência do fenômeno da extinção, o qual ele havia estabelecido como um fato. 0 desaparecimento de faunas inteiras deu-se ao longo da história do Globo, em episódios excepcionais que Cuvier denominou de revoluções. Súbitas ou não, estas catástrofes seriam produzidas por agentes operantes na atualidade em uma magnitude ampliada. Entretanto, à diferença do que podia ser verificado na observação destes, as revoluções tinham como resultado mudanças bruscas na configuração biológica e geológica das áreas que atingiam. Isto poderia ser verificado no registro geológico que apresentava em determinados estratos vestígios de alguma ruptura na continuidade de processos lentos e graduais, como os que operam na atualidade.

Foi contra esta descontinuidade que Lyell quis romper com seu Uniformitarismo. Também analisando o registro geológico e fossilifero, ele percebeu que haviam atuado, por toda a história do Globo, processos operantes na atualidade com pouca alteração de intensidade. As enormes e marcantes diferenças entre as configurações biológicas e geológicas atuais e antigas poderiam ser explicadas por meio da atuação, em um longo intervalo de tempo, dos mesmos agentes operantes na atualidade.

Ele e Cuvier analisaram fenômenos semelhantes, mas chegaram a conclusões diferentes, propondo teorias que, de certa forma, poderiam ser consideradas como antagônicas. Ambos estudaram os fósseis e os estratos que os continham, porém Cuvier voltou muito mais sua atenção para os quadrúpedes, pois, primeiramente, estava interessado em comprovar a ocorrência da extinção, e estes seriam os fósseis mais adequados porque por, naquele momento, o Globo já tinha ter sido bem explorado e havia haver pouca chance de existirem novas descobertas deste grupo que pudessem invalidar suas constatações sobre a ocorrência do fenômeno da extinção durante a história da Terra.

As faunas extintas estavam representadas em estratos que eram sucedidos por outros nos quais uma nova fauna se fazia representar. Cuvier interpretou estes dados como decorrentes de algum evento catastrófico, que extinguia os animais da região atingida ao mesmo tempo em que formava um estrato geológico caracterizado por esta fauna extinta. Para ele, este câmbio faunístico era claramente uma ruptura de continuidade dos processos que operavam, 
enquanto a referida fauna vivia naquela localidade, porque por isso os estratos em que estas faunas eram escavadas encontravam-se claramente definidos em termos geológicos.

Por sua vez, Lyell voltou-se aos fósseis de um grupo muito mais numeroso e que, portanto, apresentava uma amostra muito mais precisa para o seu projeto estatístico. As conchas fósseis do Terciário indicavam a ele que tinham estado submetidas a uma dinâmica de sucessão biótica que se dava de forma lenta e gradual, pois, seguindo a sequência temporal dos estratos em que ocorriam, podia ser constatada uma substituição gradativa e contínua dos grupos extintos, assim como o surgimento dos novos.

Esta constatação de Lyell, isto é, da existência de uma continuidade dos processos geológicos e biológicos, seria uma de suas principais divergências com a teoria catastrofista. Contudo, ainda assim, não estaríamos falando aqui de uma ruptura paradigmática total, ${ }^{42}$ já que tanto os catastrofistas como 0 uniformitarista Lyell permaneceram utilizando, eficientemente, o método atualista em suas explicações e predições.

Até mesmo nesta quebra de continuidade, provocada pelas revoluções cuvierianas, os processos envolvidos não precisavam ser diferentes dos atuais. Necessitavam ser apenas mais intensos, uma diferença que o Uniformitarismo refutava. Excetuando esta divergência, ambas as teorias, catastrofista e uniformitarista, apresentavam um sólido ponto de convergência: a utilização de leis naturais universais.

As "causas atuais" e as "revoluções" operavam consoante estas leis, pois, somente baseados neste pressuposto, tanto Lyell quanto Cuvier puderam estender temporalmente suas explicações e, com isso, aproximarem-se de uma compreensão mais precisa da história do Globo. 0 Atualismo que ambos utilizavam, mesmo que de forma diferente, estava profundamente comprometido com esta universalidade, tendo apenas thes faltado mais dados para que suas explicações a respeito dos fenômenos geológicos atingissem uma maior precisão.

Passados quase dois séculos deste debate, uma enorme gama de novos dados foi produzida. Vários destes corroboram o gradualismo lyelliano, mas também vários outros reforçam a teoria catastrofista, como, por exemplo, a extinção em massa provocada pela queda de um asteroide ocorrida no limite Cretáceo/Terciário. Todavia, por outro lado, outros dados vieram explicar a extinção massiva de espécies ocorrida no limite Permo/Triássico, em termos atualistas. Uma intensa atividade vulcânica - uma "causa atual" - teria gerado durante um intervalo de tempo relativamente grande o desequilíbrio ambiental, que resultou na extinção da enorme quantidade de espécies daquele período - um efeito catastrófico.

Assim, estas hipóteses, mesmo que estando baseadas em um Catastrofismo que, de certa forma, foi relativizado com o desenvolvimento científico, incorporaram uma forte utilização das "causas atuais" às explicações dos eventos que tiveram consequências catastróficas na configuração biológica e geológica do Globo.

\section{Notas e referências bibliográficas}

Felipe Faria é professor colaborador Universidade Federal de Santa Catarina. E-mail: felipeafaria@uol.com.br

1 Era geológica equivalente à Mesozoica (245 M.a. a 65 M.a.) (FOUCAULT, Alain; RAOULT, Jean-François. Dictionnaire de Géologie. Paris: Dunod, 2005. p. 316).

2 Rochas da era geológica Primária, correspondente à Paleozoica (570 M.a. a 245 M.a.) (FOUCAULT; RAOULT, op. cit., p. 283).

3 DE LUC, Jean-André. Lettres physiques et morales sur I'histoire de la Terre et de l'homme adresses a la reine de la Grande Bretagne I. Paris: Duchesne, 1779a, p. 449-489 e DE LUC, Jean-André. An elementary treatise on Geology determining fundamental points in that science and that containing an examination of some moderns geological systems and particularly of the huttonian theory of the earth. Londres: F.C. \& J. Rivington, 1809. p. 37-39.

4 DE LUC, Jean-André. Lettres physiques et morales sur l'histoire de la Terre et de l'homme adresses a la reine de la Grande Bretagne I. Paris: Duchesne, 1779a, p. 239-242 e DE LUC, Jean-André. Lettres physiques et morales sur I'histoire de la Terre et de l'homme adresses a la reine de la Grande Bretagne II. Paris: De Tune, 1779. p. 469-505.

5 Hutton expôs sua teoria geológica em seu livro de 1788, intitulado: Theory of the earth; or an investigation of the laws observable in the composition, 
dissolution and restoration of the land upon the globe [Teoria da Terra; ou uma investigação das leis observáveis na composição, dissolução e restauração da terra sobre 0 Globo].

60 matemático e professor de História Natural Playfair foi um dos grandes responsáveis pela divulgação das ideias de Hutton por intermédio de seu livro, Ilustrations of the Huttonian theory of the Earth [llustrações da teoria huttoniana da Terra]. Escrito em 1802, esta obra popularizou e promoveu as teorias de Hutton, tornando a leitura do grande livro de Hutton mais agradável e assim atingindo o grande público (ALLABY, Michael. Dictionary of earth sciences. Oxford: Oxford University Press, 2008. p. 443).

7 RUDWICK, Martin. Bursting the limits of time: The reconstruction of geohistory in the age of Revolution. Chicago: University of Chicago Press, 2005. p. 465-466.

8 CUVIER, Georges. Recherches sur les ossemens fossiles oú l'on rétablit les caracteres de plusiers espèces d'animaux que les révolutions du globe paroissent avoir détruites, I. Paris: Deterville, 1812. p. 12-13.

9 CUVIER, op. cit., p. 68-73.

10 CUVIER, op. cit., p. 16-17.

11 CUVIER, op. cit., p. 10-12.

12 LYELL, Charles. Principles of Geology, being an inquiry how far the formerchanges of the earth surface are referable to causes now in operation, III. 3. ed. Londres: John Murray, 1835. p. 250.

13 ... [Trata-se do subitítulo do referido livro] sendo uma tentativa de explicar as mudanças anteriores da superfície da Terra, por fazer referência às causas agora em operação. Publicado em três volumes, durantes os anos de 1830, 1832 e 1833, respectivamente.

14 CUVIER, op. cit., p. 25-33.

15 LYELL, Charles. Principles of Geology, being an attempt to explain the former changes of the earth's surface, by reference to causes now in operation, I. Londres: John Murray, 1830. p. 75-91 e LYELL, Charles. Principles of Geology, being an attempt to explain the former changes of the earth's surface, by reference to causes now in operation, III. Londres: John Murray, 1833. p. 1-7.

16 LYELL, Katherine M. (Ed.). Life, letters and journals of Sir Charles Lyell, Bart, author of "Principles of Geology", I. Londres: John Murray, 1881. p. 234.

17 BAKER, Victor R. Catastrophism and uniformitarism: Logical roots and current relevance in Geology. In: BLUNDEL, Dereck J.; SCOTT, Andrew C. (Ed.). Lyell: The past is the key to the present. Londres: Geological Society of London, 1998, p. 171-182, special publications, n. 143.

18 RUSE, Michael. The Darwinian revolution: Science red in tooth and claw. Chicago: University of Chicago Press, 1999. p. 40 e RUDWICK, Martin. Uniformity and progression: Reflections on the structure of geological theory in the age of Lyell. In: ROLLER, Duane H. D. (Ed.). Perspective in the History of Science and technology. Norman: Oklahoma University Press, 1971. p. 225.

19 CANNON, Walter F. Charles Lyell is permited to speak for himself: An abstract. In: SCHNEER, Cecil J. (Ed.). Toward a History of Geology. Cambridge: The M.I.T. Press, 1969. p. 79 e RUDWICK, op. cit., 1971, p. 212-213 e RUSE, op. cit., p. 40.

20 CUVIER, op. cit., , p. 68-73 e MAYR, Ernst. The growth of biological thought: Diversity, evolution and inheritance. Cambridge: Belknap Press of Harvard University Press, 1982. p. 374-375.

21 "Por unidade de tipo entende-se aquela concordância fundamental de estrutura, que observamos nos seres organizados pertencentes à mesma classe, a qual independe inteiramente de seus hábitos de vida. Pela minha teoria, a unidade de tipo é explicada por unidade de descendência" (DARWIN, Charles. On the origin of species by means of natural selection or the preservation of favoured races int the struggle for life. Londres: Murray, 1859. p. 233).

22 RUDWICK, Martin. Lyell and the Principles of Geology. In: BLUNDEL, Dereck J.; SCOTT, Andrew C. (Ed.). Lyell: The past is the key to the present. Londres: Geological Society of London, 1998, p. 19, special publications, n. 143.

23 LYELL, Charles. The Geological evidences of the antiquity of man, with remarks on theories of the origin of species by variation. Londres: John Murray, 1863. p. 407-417 e RUDWICK, op. cit., 1998, p. 19.

24 WHEWELL, W. [Review of] Principles of geology, being an attempt to explain the former changes of the Earth's surface, by reference to causes now in operation. By Charles Lyell, Esq. F. R. S. Professor of Geology in King's College, London. The British Critic, Quarterly Theological Review, and Eclesiastical Record, v. 9, p. 206, 1831.

25 WHEWELL, William. [Review of] Principles of geology, being an attempt to explain the former changes of the Earth's surface, by reference to causes now in operation. By Charles Lyell, Esq. F. R. S. Professor of Geology in King's College, London. v. II. The Quarterly Review. Londres: John Murray, v. 47, p. 104, 1832.

26 WHEWELL, William. [Review of] Principles of geology, being an attempt to explain the former changes of the Earth's surface, by reference to causes now in operation. By Charles Lyell, Esq. F. R. S. Professor of Geology in King's College, London. v. II. The Quarterly Review. Londres: John Murray, v. 47, p. $126,1832$.

270 Princípios de Geologia somente foi publicado na França entre os anos 1843 e 1848. No final do mesmo ano da publicação do primeiro volume na Inglaterra (1830), Amy Boué (1794-1881), secretário da Sociedade Geológica da França, ao ler um relatório sobre o progresso da Geologia, nem faria menção ao livro de Lyell. De acordo com EzioVaccari, a dogmática apresentação da teoria uniformitarista seria objeto de frequentes críticas por parte dos europeus continentais (VACCARI, Ezio. Lyell's reception on the continent of Europe: A contribution to an open historiographical problem. In: BLUNDEL, Dereck J.; SCOT, Andrew C. (Ed.). Lyell: The past is the key to the present. Londres: Geological Society of London, 1998. p. 47-49, Special Publication, n. 143.

28 VACCARI, op. cit., p. 47-48.

29 Geólogo inglês, que ao longo de sua carreira teve como principal objeto de estudo as rochas do Secundário, trabalho com o qual ele estabeleceu o Sistema Siluriano (443 M.a. a 417 M.a.). Em 1828, juntamente com Lyell, iniciou uma viagem de estudos estratigráficos e geomorfológicos pela Europa continental, começando pela região do Massivo Central - França.

30 LYELL, Charles; MURCHISON, Roderick. On the escavation of valleys, as illustrated by the volcanic rock of central France. The Edinburgh New Philosophical Journal, Edinburgo, Adam Black, p. 15-47, 1829.

31 CROIZET, Jean-Baptiste; JOBERT, Antoine C. Recherches sur les ossemens fossiles de Puy-de-Dome. Paris: Les Principaux Libraires, 1828. p. 67-76; 105-122. 
32 A grande obra de Cuvier, Investigações sobre ossadas fósseis de quadrúpedes, de 1812, teve, posteriormente, o seu discurso preliminar destacado e publicado separadamente sob o título de "Discurso sobre as revoluções da superfície do Globo e sobre as mudanças que elas produziram no reino animal", tornando-se sua obra de divulgação que receberia o maior número de edições.

33 Academia de Ciências do Instituto da França (Académie des Sciences de I'Institut de France). Fundada em 1666 e suprimida em 1793, durante o período da Convenção, foi reaberta dois anos mais tarde integrando o Instituto Nacional de Ciências e Artes (Institut National des Sciences et des Arts), como sua primeira classe (Ciências Físicas e Matemáticas). A partir de 1803, Cuvier ocupou o cargo de secretário perpétuo desta instituição, que em 1816 retomou sua autonomia, integrando o Instituto da França.

34 CUVIER, Georges. Rapport verbal fait à I'Académie des Sciences sur um ouvrage de MM. L'abbé Croizet e Jobert aîné, intitule: Recherches sur les ossemens fossiles de Puy-de-Dôme (II). Annales des sciences naturelles. Paris: Crochard, v. 15, p. 224, 1828.

35 LYELL, Charles; MURCHISON, Roderick. On the escavation of valleys, as illustrated by the volcanic rock of central France. The Edinburgh new philosophical journal. Edinburgo: Adam Black, p. 46-47, 1829 e LYELL, Charles. Principles of Geology, being an attempt to explain the former changes of the earth's surface, by reference to causes now in operation, I. Londres: John Murray, 1830. p. 479.

36 Era geológica que teve duração entre 65 M.a. e 1,8 M.a. (FOUCAULT, Alain; RAOULT, Jean-François. Dictionnaire de Géologie. Paris: Dunod, 2005. p. 353).

37 LYELL, Katherine M. (Ed.), op. cit., p. 232-234; 246-252.

38 LYELL, Katherine M. (Ed.), op. cit., p. 249 e 252

39 RUDWICK, Martin. Charles Lyell's dream of a statistical palaeontology. Palaeontology. Londres: The Palaeontolgy Association, v. 21, p. $241,1978$.

40 Blocos de rochas com litologia diferente dos locais ou estratos onde são encontrados. Esta diferença aponta para um transporte que atualmente recebe a explicação glacial, ou seja, as movimentações de geleiras têm como um de seus efeitos o transporte de rochas. Até que a Teoria das Glaciações de Louis Agassiz (1807-1873) fosse aceita, o transporte destes blocos rochosos levantaram inúmeras discussões que envolveriam diversos geólogos, defendendo hipóteses que iam da ação das águas diluvianas até a erupção de vulcões (ALLABY, op. cit., p. 200).

41 LYELL, Charles. Principles of geology, being an attempt to explain the former changes of the earth's surface, by reference to causes now in operation, III. Londres: John Murray, 1833. p. 118-154.

42 KUHN, Thomas. The structure of scientific revolutions. Chicago: Universisty of Chicago Press, 1962. p. 10 e RUDWICK, Martin. Worlds before Adam: The reconstruction of geohistory in the age of reform. Chicago: University of Chicago Press, 2008. p. 393; 560-561

[Recebido em Março de 2012. Aceito para publicação em Fevereiro de 2014] 